\title{
Mechanism To Reduce Friction/Wear of Diesel Engines By Adding Nanoparticles
}

\author{
Parjane M. B., Dabade B. M.
}

\begin{abstract}
Present study was carried out for knowing how nanotechnology can be employed for improving the performances in tribology. A significant number of investigations have been reported on the effect of nanoparticles as oil additives. The wear and friction tests were carried on four ball oil tester using ZDDP. $\mathrm{NiO}$ and $\mathrm{MoS}_{2}$ nanoparticles in $1 \mathrm{wt} \%$ combination with mineral oil to provides the reduction in friction and wear. Much of the research suggests that even up to $1 \%$ concentrations of such particles are instrumental in reducing wear and friction. Nanoparticle additives have proved to be promising for development of Tribological properties of mineral oil. The tribological properties of typical engine oil like SAE15W40 mineral oil added with nanoparticle additives were studied and then experimental analysis was done. Investigations were performed on oil having concentrations of Zinc Dialkyl Dithio Phosphate, Molybdenum Disulfide and Nickel Oxide nanoparticles and their combinations to find that anti wear properties are improved. The evaluation of the tribological behavior pertaining to friction was determined using four ball oil testing machine TR-30L containing combination of above described nanoparticles together in base oil showed the most promising results.
\end{abstract}

Keywords : Mineral oil, Nanoparticles, Friction, Wear Scar Diameter, C.I engines.

\section{INTRODUCTION}

Recent research papers have reported that the addition of nanoparticles to lubricant is effective for the reduction of wear and friction in mechanical systems. Because of the remarkable tribological properties of nanoparticles, nanotechnology is regarded as the most revolutionary technology of the $21^{\text {st }}$ century.. For any machine to work easily, some vitality must be accommodated the sole motivation behind defeating erosion. Limiting vitality lost through grating builds the effectiveness of machines. In this manner, with regards to vitality proficiency, the noteworthiness of decreasing erosion can't be overemphasized. This is particularly obvious as oil holds proceed to decrease and vitality costs are rising persistently. Likewise, erosion and wear are two significant reasons crucial designing parts in different frameworks come up short, for

Revised Manuscript Received on May 15, 2020.

* Correspondence Author

Parjane M. B.*, Research Scholar, SGGSE\&IT Nanded, Maharashtra-431601 (India). Email: itsmanoj1539@gmail.com

Dr. Dabade B. M., Professor with department of Production Engineering, SGGSE\&IT, Nanded, Maharashtra-431601 (India). Email: bmdabade@gmail.com

(c) The Authors. Published by Blue Eyes Intelligence Engineering and Sciences Publication (BEIESP). This is an open access article under the CC BY-NC-ND license (http://creativecommons.org/licenses/by-nc-nd/4.0/) example, gears, pin joints, cylinders, orientation, camshafts, siphons, blowers, and turbines. The expense of gear, establishment, and fix identified with frictional lacks, wear, and harm puts a huge weight on any national economy [1].

Nanoparticles have been examined as added substances for ointments so as to improve extraordinary weight properties, diminishing erosion and wear, disseminating heat age and broadening instrument life too. Burden conveying limit was expanded up to $55 \%$ with $0.10 \mathrm{wt} \%$ graphene impregnation. The adequacy of nanoparticles emphatically relies upon the sort of fluid utilized, nanoparticles size and geometry just as filler fixations. The upsides of nanoparticles inside greases are that nanoparticles goes about as a third body or nano-bearing, making a moving impact between surfaces instrument, filling valleys, along these lines framing a defensive film on a superficial level or might be tribo-sintered to the surface indicating the commitment of erosion and sport decrease by inclusion of nanoparticles [2]. Nanoparticles have been examined as added substances for ointments so as to improve extraordinary weight properties, diminishing erosion and wear, disseminating heat age and broadening instrument life too. Burden conveying limit was expanded up to $55 \%$ with 0.10 wt $\%$ graphene impregnation. The adequacy of nanoparticles emphatically relies upon the kind of fluid utilized, nanoparticles size and geometry just as filler fixations. [3][4]. Additives are usually mixed into the base oil to improve its performance. It is stated that the number and amount of additives present depend on application and they are selected to enhance the base oil performance so that the combination will meet the system requirements [5].

One of the study suggested that Ni-MoS 2 nano sheets in gear oil helps in forming of a linear tribo film which increases Wear resistance and load carrying capability[6]. Some experiments were also studied where the four-ball tester is used to investigate the anti-wear and extreme pressure properties of lubricating oil at various conditions such as higher load, controlled temperature and constant rotating speed of ball [7][13]. However, the reports on the tribological performances of $\mathrm{ZDDP}-\mathrm{MoS}_{2}$ and $\mathrm{NiO}$ nanoparticles are fairly limited especially on the formation of $\mathrm{MoS}_{2}$ lubricating film [8]. Therefore, it is meaningful to investigate the influences of the $\mathrm{MoS}_{2}$ addition on the tribological behavior of ZDDP and $\mathrm{NiO}$ nanoparticles. This work is a kind of exploration for using the Nano material impregnated oils and would give an insight into tribological performance parameters. 


\section{Mechanism To Reduce Friction/Wear of Diesel Engines By Adding Nanoparticles}

\section{METHODOLOGY}

\section{A. Material Preparation}

The additives are mixed into in the base oil i.e. SAE 15W40 lubricating oil. For preparing the oil samples impregnated with nano particles, a magnetic stirrer is used for mixing of additive particles in the base oil. The weight of the oil samples was taken with the help of precision balance .Oleic acid is used as a surfactant in the dispersion process to reduce particles agglomeration and thus improves the dispersion stability of additive particles in lubricating oil [9].

\section{B. Sample Preparation with various proportions}

In the present work, thirteen samples are prepared by different proportions ranges of nanoparticles from $0.3 \%$ to $3.0 \mathrm{wt} \%$ in SAE 15W40 lubricating oil. All samples are prepared by using precision balance and magnetic stirrer at various proportions. Branded mineral oil (SAE 15W40) and nano-oil samples were prepared by diffusing various concentrations of 24 to $34 \mathrm{~nm}$ sized NiO, ZDDP and $\mathrm{MoS}_{2}$ nanoparticles in conventional diesel engine oil. The samples could be stabilized with only the addition of an appropriate amount of surfactant (oleic acid). Homogenization of mixture of solid Nano particles and base oil was done by using magnetic stirrer.

\section{Experimental Setup for Wear Test: Four-Ball Test Rig}

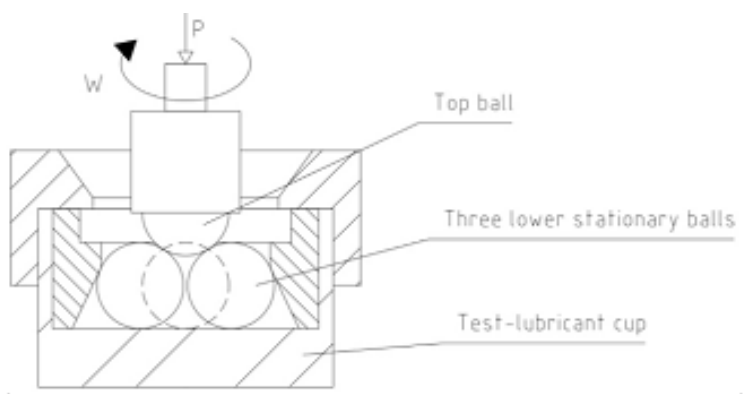

Figure1. Four-Ball tester ball arrangements (TR-30L) [10].

Testing was performed to determine the coefficient of friction using four ball tester (TR-30L). Features of both Extreme Pressure and wear testing machines are combined in TR-30L. In this machine three steel balls of $12.7 \mathrm{~mm}$ were clubbed together and covered with various samples of the prepared oils, then a fourth ball of same diameter held in a special collet inside spindle on the top rotated by an AC motor. During the rotary action of the top ball on the three stationary balls which are immersed in sample oil. Under the additional provision to control and heat the oil sample, the clamping ring and tightening lock nut in the ball pot. The load, speed, temperature and time that were maintained during the test were $392.4 \mathrm{~N}, 1200 \mathrm{rpm}, 750^{\circ} \mathrm{C}$ and 3600 seconds respectively. Normal loading on the balls was done by loading lever and dead weights placed on loading pan [11]. The ball pot is placed over the loading lever on a thrust bearing \& plunger. Measurement of normal load is done with the help of a load cell arrangement. Frictional torque exerted on the balls is also measured[12]. balls are kept in the above described position with the help of

\section{RESULTS AND DISCUSSIONS}

\section{A. Coefficient of Friction (COF)}

In this work the frictional torque was recorded torque values and the coefficients of friction of the lubricants were determined from the graphs indicated from the software. From the Graph 1, its evident that sample L has reduced COF at applied normal load. Base oil has 0.10169 as the value of COF whereas the best sample $L$ has 0.05303 as its COF. However, the same sample L shows lower COF as compared to other samples. It is evident that the additives in sample $\mathrm{L}$ have an adverse effect on COF. Hence sample L with additives is effective in reducing friction. This is because $\mathrm{MoS}_{2}, \mathrm{NiO}$ and ZDDP prove to be an anti-wear and antioxidant additives for SAE15W40 lubricating oil.

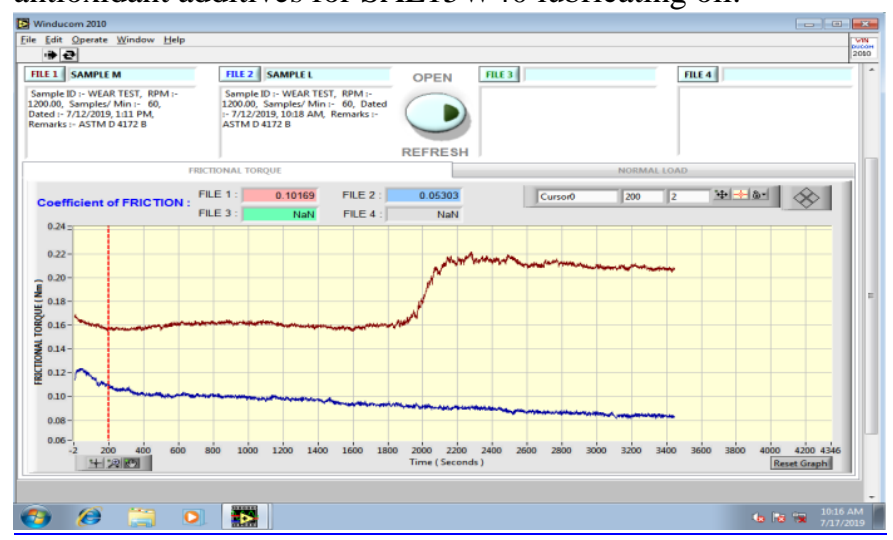

Graph1, Comparative graph between ample $\mathrm{L}$ and SAE15W40 Lubricating oil for Coefficient of Friction. In above graph red line indicated sample BO (SAE15W40 OIL) and blue line indicates sample L.

\section{B. Wear Scar Diameter(WSD)}

Figure 2, 3 and 4 illustrate the images of Wear Scars impinged on ball specimens with various samples of oil impregnated with nanoparticles such as ZDDP, NiO and $\mathrm{MoS}_{2}$ at $1 \mathrm{wt} \%$ of each which proves to be the best sample $\mathrm{L}$ having WSD as $359 \mu \mathrm{m}$. The base oil SAE $15 \mathrm{~W} 40$ has WSD value of $432 \mu \mathrm{m}$.

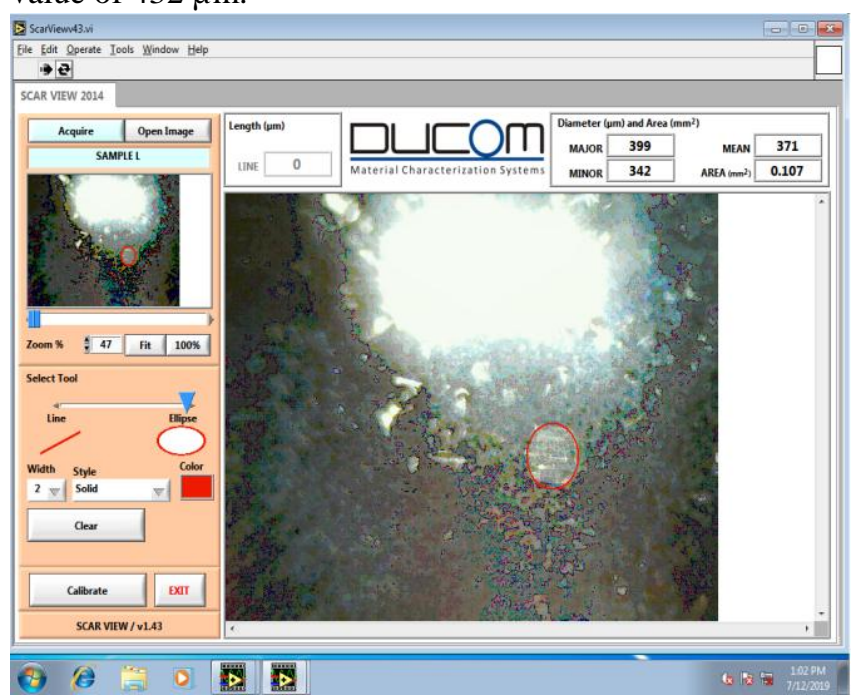

Figure 2. Image of Ball 1 of Best sample $L$

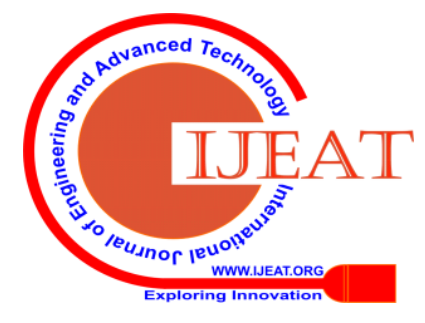




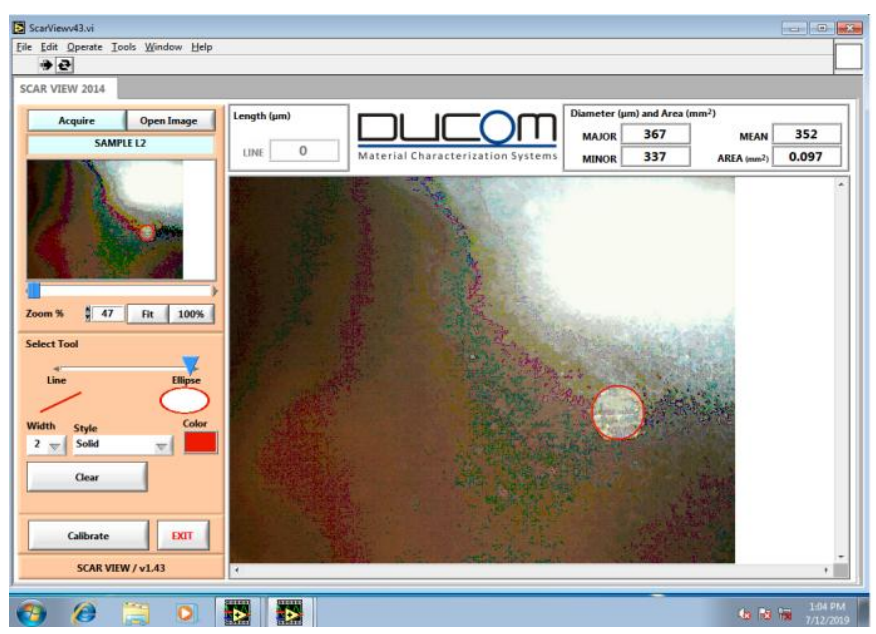

Figure 3. Image of Ball 2 of Best sample $L$

\section{Extreme Pressure}

The test was also done for load carrying capacity of mineral oil and best sample L on four ball tester using ASTM 2783D standard [9]. Extreme pressure results stated that pass load and weld load for base oil (SAE 15W40) are 150 and 200kg respectively whereas for best sample $\mathrm{L}(1 \mathrm{wt} \%$ of all nanoparticles) has 200 and $250 \mathrm{~kg}$ pass ans weld load. The results have improved because of nano additives in mineral oil.

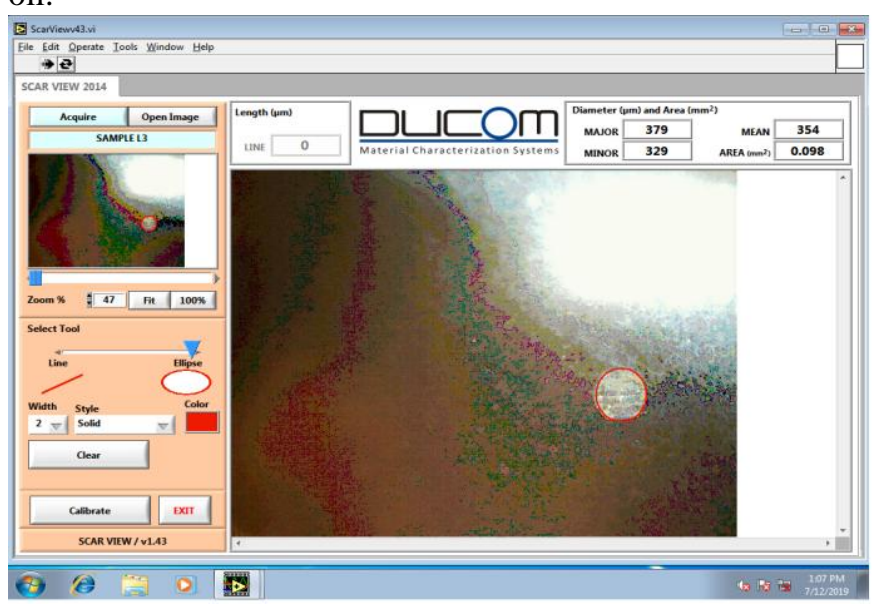

Figure 4. Image of Ball 3 of Best sample $L$

\section{CONCLUSIONS}

The findings that can be illustrated from the above are :

- The used nanoparticles with base oil remained stable, without deposition.

- The tribological investigation of mineral oil with $1 \%$ wt of all nanoparticles proved to be suitable friction modifier and antiwear agent as compared to SAE 15W40 mineral oil. Wear was reduced by $16 \%$ by adding nanoparticles by $1 \%$ wt and load carrying capacity which is important parameter for any lubricant has increased by $25 \%$.

\section{FUTURE SCOPE}

The research work can be done to determine performance under extreme pressure condition when the concentrations are changed. Calculate the load carrying capacity of nanoparticles when the proportions of added samples are changed. Focus on improvement of fire point, flash point and viscosity is also a good research area.

\section{ACKNOWLEDGEMENT:}

Authors are thankful to Shri Guru Gobind Singhji Institute of Technology and Engineering, Department of Mechanical and Production Engineering. Also they are indebted by the help of Dr. Tungikar \& Dr. Nandedkar for the guidance and help during the experimental work.

\section{REFERENCES}

1. M.A. Maleque, "Effect of mechanical factors on tribological properties of palm oil methyl ester blended lubricant," in Elsevier science, Wear 239, 2000, pp. 117-125.

2. Muhammad Ilman Hakimi Chua Abdullaha, Mohd Fadzli Bin Abdollaha,b, Hilmi Amiruddina, Noreffendy Tamaldina, Nur Rashid Mat Nuria, "Optimization of Tribological Performance of $\mathrm{hBN} / \mathrm{AL}_{2} \mathrm{O}_{3}$ Nanoparticles as Engine Oil Additives", in The Malaysian International Tribology Conference 2013, MITC2013, pp313-319.

3. Kraiput Cheenkachorn, "Development of engine oil using palm oil as a base stock for four stroke engines," in Science Direct, Energy 35, 2010, pp. 2552-2556.

4. Laura Peña-Parás, Jaime Taha-Tijerina, Lorena Garza, Demófilo Maldonado-Cortés, Remigiusz Michalczewski, Carolina Lapray, "Effect of $\mathrm{CuO}$ and $\mathrm{Al}_{2} \mathrm{O}_{3}$ nanoparticle additives on the tribological behavior of fully formulated oils" in Wear Journal, Elsevier science, 2015, pp. 1256-1261.

5. M.A. Kalam, "Friction and wear characteristics of waste palm oil contaminated lubricants," in International Journal of Mechanical and Material Engineering, Vol.6, 2011, pp. 431-436.

6. Ankit Kotia, Gaurab Kumar Ghosh Isha, Srivastava Piyush Deval, Subrata Kumar Ghosh," Mechanism for improvement of friction/wear by using $\mathrm{Al}_{2} \mathrm{O}_{3}$ and $\mathrm{SiO}_{2} /$ Gear oil nanolubricants"in Journal of Alloys and Compounds, Volume 782, 25 April 2019, Pages 592-599

7. T. Chiong Ing, "Tribological behavior of refined bleached and deodorized palm olein in different load using a four ball tribotester," in Elsevier science, Scientis Iranica B, 2012, pp. 1487-1492.

8. 8] D. Md. Razak, "Lubrication on the curve surface structure using Palm oil and Mineral oil," in Elsevier science, 2013, pp. 607-612.

9. M.H. Mosarof, "Implementation of palm biodiesel based on economic aspects, performance, emission and wear characteristics," in Elsevier science, 2015, pp. 617-629.

10. Kok-Hou Tan, "Zeolite nanoparticles as effective antioxidant additive for the preservation of palm oil-based lubricant," in Journal of the Taiwan Institute of Chemical Engineers, Elsevier science, 2015, pp. 1-7.

11. Gautam Yadav, "Tribological analysis of extreme pressure and anti-wear properties of engine lubricating oil using four ball tester," in Elsevier science, 2018, pp. 248-253.

12. Fatima Borda, "Experimental Investigation of the Tribological Behaviour of Lubricants with additive containing copper nanoparticles," in Tribology International, 2018, pp. 52-58.

13. Juozas Padgurskas, "Tribological Properties of Lubricant Additives of $\mathrm{Fe}, \mathrm{Cu}$ and $\mathrm{Co}$ nanoparticles" in Tribology International, 2013, pp. 224-232.

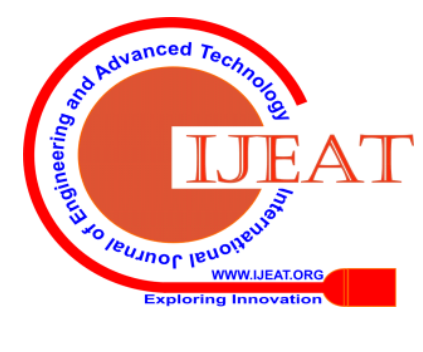


Mechanism To Reduce Friction/Wear of Diesel Engines By Adding Nanoparticles

\section{AUTHORS PROFILE}

Mr. Manoj Baburao Parjane completed his Bachelor's Degree in Mechanical Engineering from Pravara Rural Engineering College, Loni affiliated to University of Pune, Maharashtra, India in 2001. Then in 2009 he got his Master's Degree in Mechanical Engineering from Swami Ramanand Tirth Marathwada University Nanded, Maharashtra, India. Later in 2011 he got registered for Ph.D. in Mechanical Engineering at Shri Guru Gobind Singhji Institute of Engineering \& Technology, Nanded. He has also worked as Principal at Padmashree Dr. Vitthalrao Vikhe Patil Institute of Technology \& Engineering Polytechnic at Loni. Currently he is working as Associate Professor in the Mechanical Engineering Department of Pravara Rural Engineering College, Loni, Maharashtra

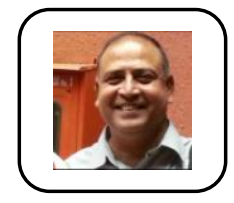

Dr. Balaji Marotrao Dabade, completed his Bachelor's Degree in Production Engineering from VJTI, Mumbai affiliated to Mumbai University in 1982, MTech in Production Engineering from NIT, Rourkela, in 1989. He completed PhD in Mechanical Engineering from IIT Kharagpur India. He has worked as Director of SGGS. He has guided $10 \mathrm{PhD}$ students and numerous MTech students in the fields of Mechanical and Production Engineering, He has a huge experience of teaching and research at SGGS Nanded, Maharashtra. 